\title{
Analysis of water temperature distribution in various type of absorber in solar thermal by 3-D finite element method
}

\author{
Padej Pao-la-or, Issaraporn Amornsawatwattanaa \\ School of Electrical Engineering, Institute of Engineering, Suranaree University of Technology, \\ Nakhon Ratchasima 30000, Thailand
}

\begin{abstract}
This paper present mathematical model of temperature distribution in solar thermal which performs in second-order partial differential equation. Solar thermal analysis uses copper absorber, aluminum absorber, and anodized aluminum absorber to compare temperature distribution of water in pipe from three types of absorber. The paper simulation using 3-D finite element method that all the coded developed by MATLAB program and show the graphical represent for temperature which varies with time of glass, absorber, pipe, water, foil, and foam temperature in various type of absorber.
\end{abstract}

Keywords: Solar thermal, 3-D finite element method (3-D FEM), computer simulation, temperature, absorber

\section{Introduction}

It is well known that the sun is the vital energy. However, there are different ways to utilize the solar energy in thermal form. Mostly, for the household purposes, it used to energize water at various temperatures. Moreover, in Thailand, many household and hotels were still used water heater although it is in the warm zone as a tropical country. In this study, the method to produce the solar thermal which helps to conserve energy and minimize the global warming were presented.

Recently, for temperature calculation, the numerical approximation techniques such as finite difference (FD) or finite element methods (FEM) have been utilized in analyzation of solar thermal [1]. Furthermore, due to the lack of accuracy in nonlinear temperature involvement, the first approach is not frequently used for this occasion [1]. Nowadays, the FEM has become more appropriate for resolving temperature problems in a broad range due to its flexibility, and accuracy. Consequently, in term of potency, the FEM to the solar thermal is more applicable than the FD due to advantages of flexibility and efficiency [2]-[5].

Additionally, the temperature distribution in solar thermal is inspected. With the aid of a set of partial differential equations (PDE), the evaluations are acquired. In Section 2, the mathematical model of temperature in solar thermal based on a set of heat transfer equations are stated. The 3-D FEM by using Galerkin approach applied from solar thermal to obtain temperature distribution is explained in Section III. Likewise, the linear tetrahedron elements have also been discretized the domain of disquisition on the 3-D FEM. Section 3 contains the carryout simulations initiated on the 3-D FEM method. Section 4 specifies the solar thermal dimensions and parameters. In programming temperature, MATLAB program is instructed for coded analysis to compare temperature distribution of water from three types of absorber: copper absorber [6], aluminum absorber [6], and anodized aluminum absorber [7]. The data on the test precedent and simulation results are displayed in Section 5 for invertigation. The last section concluded the conclusion of the study.

\footnotetext{
* Manuscript received July 23, 2018; revised April 14, 2019.

Corresponding author. Tel.:+66-44-22-4400; E-mail address: padej@sut.ac.th

doi: $10.12720 /$ sgce.8.4.461-469
} 


\section{Modeling of Temperature for Solar Thermal}

Equation (1) is shown 3-D heat transfer equation with the heat source is used to obtain the temperature distribution in solar thermal and Equation (1) is partial differential equations (PDE), so it uses FEM [8].

$$
k \frac{\partial}{\partial x} \frac{\partial T}{\partial x}+k \frac{\partial}{\partial y} \frac{\partial T}{\partial y}+k \frac{\partial}{\partial z} \frac{\partial T}{\partial z}-\rho c\left(u \frac{\partial T}{\partial x}+v \frac{\partial T}{\partial y}+w \frac{\partial T}{\partial z}\right)+Q=\rho c \frac{\partial T}{\partial t}
$$

Where,

$T$ is temperature $\left({ }^{\circ} \mathrm{C}\right)$

$k$ is thermal conductivity $\left(\mathrm{W} / \mathrm{m} \cdot{ }^{\circ} \mathrm{C}\right)$

$c$ is the capacity of the specific heat $\left(\mathrm{J} / \mathrm{kg} \cdot{ }^{\circ} \mathrm{C}\right)$

$\rho$ is the density of the mass $\left(\mathrm{kg} / \mathrm{m}^{3}\right)$

$Q$ is internal heat generation $\left(\mathrm{W} / \mathrm{m}^{3}\right)$

$u, v, w$ is axis velocity of water flow $\mathrm{x}, \mathrm{y}, \mathrm{z}$, respectively $(\mathrm{m} / \mathrm{sec})$

\section{3-D FEM for Solar Thermal}

\subsection{Discretization}

The domain of study with the 3-D finite element method can be discretized by using linear tetrahedron elements. Solid Work for 3-D grid generation can be accomplished this characteristic. Fig. 1. displays details of solar thermal and Fig. 2. displays mesh of solar thermal and mesh of pipe and water. The solar thermal is indicated at the first layers is glass prevent dust and heat losing. The second layer is absorber which is absorbs solar radiation and converts it to be heat energy into the fluid. This layer for diagnose the property of each material which are copper absorber, aluminum absorber, and anodized aluminum absorber, respectively. The third layer is pipe and water. The absorber from second layer transfers heat to pipe then pipe transfers the heat to water. The fourth layer is foil, which is insulation and the last layer is foam, which is also insulation. The 76,994 nodes and 442,008 elements were contained in the region domain.

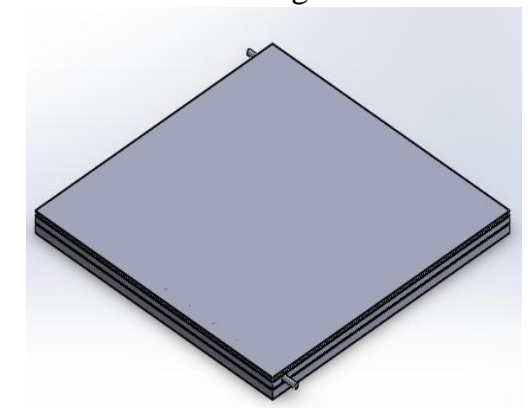

a) Details of solar thermal

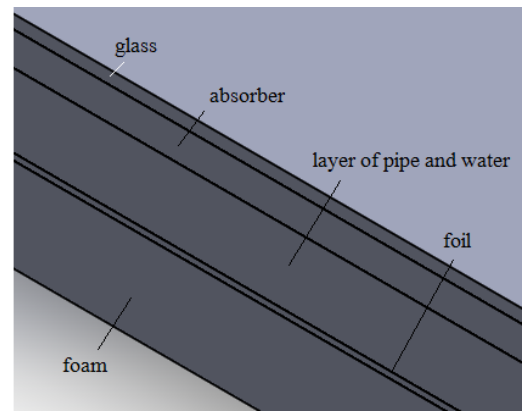

b) Details of each layer

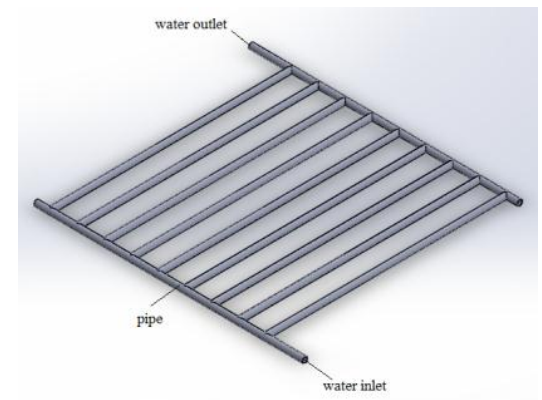

c) Details of pipe and water

Fig. 1. Details of solar thermal 


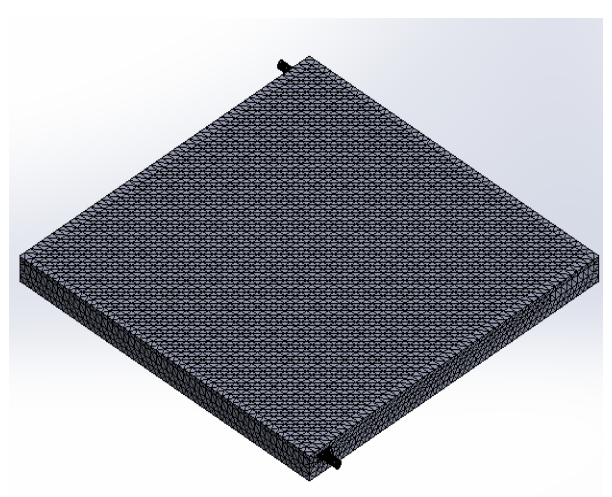

a) Mesh of solar thermal

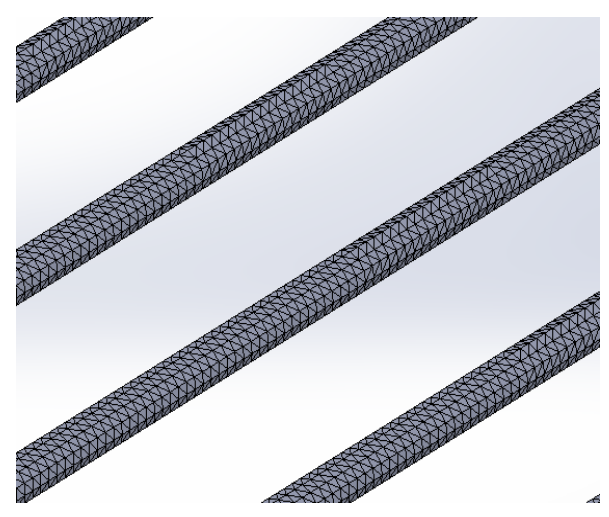

b) Mesh of pipe and water

Fig. 2. Mesh of solar thermal

\subsection{Formulation of finite element}

In the particular method of weighted residual for the weighting functions that are similar in the shape function, Galerkin method was applied in heat transfer equations for controlling each component from the derived formula. For this paper, the 4-node tetrahedron element (three-dimensional linear element) was used for the shape function for 3-D finite element method. According to this method, in Equation (2) and Equation (3) are expressed corresponding with temperature [9].

$$
T(x, y, z)=T_{1} N_{1}+T_{2} N_{2}+T_{3} N_{3}+T_{4} N_{4}
$$

Where,

$N_{i}, i=1,2,3,4$ is the element shape function. And the $T_{i}, i=1,2,3,4$ is the temperature of each node $(1,2,3,4)$ of the elements, then

$$
N_{i}=\frac{1}{6 V}\left(a_{i}+b_{i} x+c_{i} y+d_{i} z\right)
$$

Where,

$V$ is the volume of the tetrahedron element as in Equation (4).

$$
V=\frac{1}{6}\left|\begin{array}{llll}
1 & x_{1} & y_{1} & z_{1} \\
1 & x_{2} & y_{2} & z_{2} \\
1 & x_{3} & y_{3} & z_{3} \\
1 & x_{4} & y_{4} & z_{4}
\end{array}\right|
$$

The positional coefficient defined by

$$
\begin{array}{ll}
a_{1}=x_{4}\left(y_{2} z_{3}-y_{3} z_{2}\right)+x_{3}\left(y_{4} z_{2}-y_{2} z_{4}\right)+x_{2}\left(y_{3} z_{4}-y_{4} z_{3}\right) & b_{1}=y_{4}\left(z_{3}-z_{2}\right)+y_{3}\left(z_{2}-z_{4}\right)+y_{2}\left(z_{4}-z_{3}\right) \\
a_{2}=x_{4}\left(y_{3} z_{1}-y_{1} z_{3}\right)+x_{3}\left(y_{1} z_{4}-y_{4} z_{1}\right)+x_{1}\left(y_{4} z_{3}-y_{3} z_{4}\right) & b_{2}=y_{4}\left(z_{3}-z_{2}\right)+y_{1}\left(z_{3}-z_{4}\right)+y_{3}\left(z_{4}-z_{1}\right) \\
a_{3}=x_{4}\left(y_{1} z_{2}-y_{2} z_{1}\right)+x_{2}\left(y_{4} z_{1}-y_{1} z_{4}\right)+x_{1}\left(y_{2} z_{4}-y_{4} z_{2}\right) & b_{3}=y_{4}\left(z_{3}-z_{2}\right)+y_{2}\left(z_{1}-z_{4}\right)+y_{1}\left(z_{4}-z_{2}\right) \\
a_{4}=x_{3}\left(y_{2} z_{1}-y_{1} z_{2}\right)+x_{2}\left(y_{1} z_{3}-y_{3} z_{1}\right)+x_{1}\left(y_{3} z_{2}-y_{2} z_{3}\right) & b_{4}=y_{3}\left(z_{3}-z_{2}\right)+y_{1}\left(z_{2}-z_{3}\right)+y_{2}\left(z_{3}-z_{1}\right) \\
c_{1}=x_{4}\left(z_{2}-z_{3}\right)+x_{2}\left(z_{3}-z_{4}\right)+x_{3}\left(z_{4}-z_{2}\right) & d_{1}=x_{4}\left(y_{3}-y_{2}\right)+x_{3}\left(y_{2}-y_{4}\right)+x_{2}\left(y_{4}-y_{3}\right)
\end{array}
$$




$$
\begin{array}{ll}
c_{2}=x_{4}\left(z_{3}-z_{1}\right)+x_{3}\left(z_{1}-z_{4}\right)+x_{1}\left(z_{4}-z_{3}\right) & d_{2}=x_{4}\left(y_{1}-y_{3}\right)+x_{1}\left(y_{3}-y_{4}\right)+x_{3}\left(y_{4}-y_{1}\right) \\
c_{3}=x_{4}\left(z_{1}-z_{2}\right)+x_{1}\left(z_{2}-z_{4}\right)+x_{2}\left(z_{4}-z_{1}\right) & d_{3}=x_{4}\left(y_{2}-y_{1}\right)+x_{2}\left(y_{1}-y_{4}\right)+x_{1}\left(y_{4}-y_{2}\right) \\
c_{4}=x_{3}\left(z_{2}-z_{1}\right)+x_{2}\left(z_{1}-z_{3}\right)+x_{1}\left(z_{3}-z_{2}\right) & d_{4}=x_{3}\left(y_{1}-y_{2}\right)+x_{1}\left(y_{2}-y_{3}\right)+x_{2}\left(y_{3}-y_{1}\right)
\end{array}
$$

From Equation (1) is Galerkin approach equation as referring to the differential equation was then adapted by using the weighted residual method, in which element domain $V$ as in Equation (4) was done by using the integrations as in Equation (5) [10].

$$
\begin{aligned}
& \int_{V} N_{n} \rho c \frac{\partial T}{\partial t} d V+\int_{V} k\left(\frac{\partial N_{n}}{\partial x} \frac{\partial T}{\partial x}+\frac{\partial N_{n}}{\partial y} \frac{\partial T}{\partial y}+\frac{\partial N_{n}}{\partial z} \frac{\partial T}{\partial z}\right) d V+\int_{V} N_{n} \rho c\left(u \frac{\partial T}{\partial x}+v \frac{\partial T}{\partial y}+w \frac{\partial T}{\partial z}\right) d V+\int_{\Gamma} N_{n}(h T) d \Gamma \\
& =\int_{V} N_{n} Q d V+\int_{\Gamma} N_{n}\left(h T_{\infty}\right) d \Gamma
\end{aligned}
$$

In the compact matrix form,

$$
\begin{aligned}
& {[C]_{4 \times 4}\{\dot{T}\}_{4 \times 1}+\left[\left[K_{c}\right]+\left[K_{v}\right]+\left[K_{h}\right]\right]_{4 \times 4}\{T\}_{4 \times 1}=\left\{Q_{Q}\right\}_{4 \times 1}+\left\{Q_{h}\right\}_{4 \times 1}} \\
& {[C]_{4 \times 4}=\frac{\rho c V}{20}\left[\begin{array}{cccc}
2 & 1 & 1 & 1 \\
1 & 2 & 1 & 1 \\
1 & 1 & 2 & 1 \\
1 & 1 & 1 & 2
\end{array}\right]} \\
& {\left[K_{c}\right]_{4 \times 4}=\frac{k}{36 V}\left[\begin{array}{cccc}
b_{1} b_{1}+c_{1} c_{1}+d_{1} d_{1} & b_{1} b_{2}+c_{1} c_{2}+d_{1} d_{2} & b_{1} b_{3}+c_{1} c_{3}+d_{1} d_{3} & b_{1} b_{4}+c_{1} c_{4}+d_{1} d_{4} \\
& b_{2} b_{2}+c_{2} c_{2}+d_{2} d_{2} & b_{2} b_{3}+c_{2} c_{3}+d_{2} d_{3} & b_{2} b_{4}+c_{2} c_{4}+d_{2} d_{4} \\
& & b_{3} b_{3}+c_{3} c_{3}+d_{3} d_{3} & b_{3} b_{4}+c_{3} c_{4}+d_{3} d_{4} \\
& & & b_{4} b_{4}+c_{4} c_{4}+d_{4} d_{4}
\end{array}\right]} \\
& {\left[K_{h}\right]_{4 \times 4}=\frac{h V}{20}\left[\begin{array}{cccc}
2 & 1 & 1 & 1 \\
1 & 2 & 1 & 1 \\
1 & 1 & 2 & 1 \\
1 & 1 & 1 & 2
\end{array}\right]} \\
& {\left[K_{v}\right]_{4 \times 4}=\frac{\rho c}{24}\left[\begin{array}{llll}
u b_{1}+v c_{1}+w d_{1} & u b_{2}+v c_{2}+w d_{2} & u b_{3}+v c_{3}+w d_{3} & u b_{4}+v c_{4}+w d_{4} \\
u b_{1}+v c_{1}+w d_{1} & u b_{2}+v c_{2}+w d_{2} & u b_{3}+v c_{3}+w d_{3} & u b_{4}+v c_{4}+w d_{4} \\
u b_{1}+v c_{1}+w d_{1} & u b_{2}+v c_{2}+w d_{2} & u b_{3}+v c_{3}+w d_{3} & u b_{4}+v c_{4}+w d_{4} \\
u b_{1}+v c_{1}+w d_{1} & u b_{2}+v c_{2}+w d_{2} & u b_{3}+v c_{3}+w d_{3} & u b_{4}+v c_{4}+w d_{4}
\end{array}\right]} \\
& \left\{Q_{h}\right\}_{4 \times 1}=\frac{h T_{\infty} V}{4}\left[\begin{array}{l}
1 \\
1 \\
1 \\
1
\end{array}\right] \\
& \left\{Q_{Q}\right\}_{4 \times 1}=\frac{Q V}{4}\left[\begin{array}{l}
1 \\
1 \\
1 \\
1
\end{array}\right]
\end{aligned}
$$


where,

$h$ is convective heat transfer $(\mathrm{kJ} / \mathrm{kg})$

$T_{\infty}$ is ambient temperature $\left({ }^{\circ} \mathrm{C}\right)$

The simulation of solar thermal in temperature distribution needs to be discretized such as Equation (5) the continuation of discretization method shown in Equation (13). Therefore, the time-dependent field is improved by discretizing the time. For endeavor on this task, forward difference method $(\beta=0)$, backward difference method $(\beta=1)$, and Crank-Nicholson method $(\beta=1 / 2)$, the backword difference is used as shown in Equation (14) due to its convergence [11].

$$
\begin{aligned}
& \beta\{\dot{T}\}^{t+\Delta t}+(1 / \beta)\{\dot{T}\}^{t}=\frac{\{T\}^{t+\Delta t}-\{T\}^{t}}{\Delta t} \\
& \{\dot{T}\}^{t+\Delta t}=\frac{\{T\}^{t+\Delta t}-\{T\}^{t}}{\Delta t}
\end{aligned}
$$

The finite element estimate expression is a $4 \times 4$ matrix for one element containing four nodes. In the calculation of all elements in the system of $n$ nodes, $n \times n$ matrix as the sizable is the system equation.

\section{Dimension and Parameter of Solar Thermal}

The dimension of solar thermal is shown in Fig. 3. and parameter of solar thermal are provided in Table 1. And input details for thermal analysis are provided in Table 2. [6], [12].
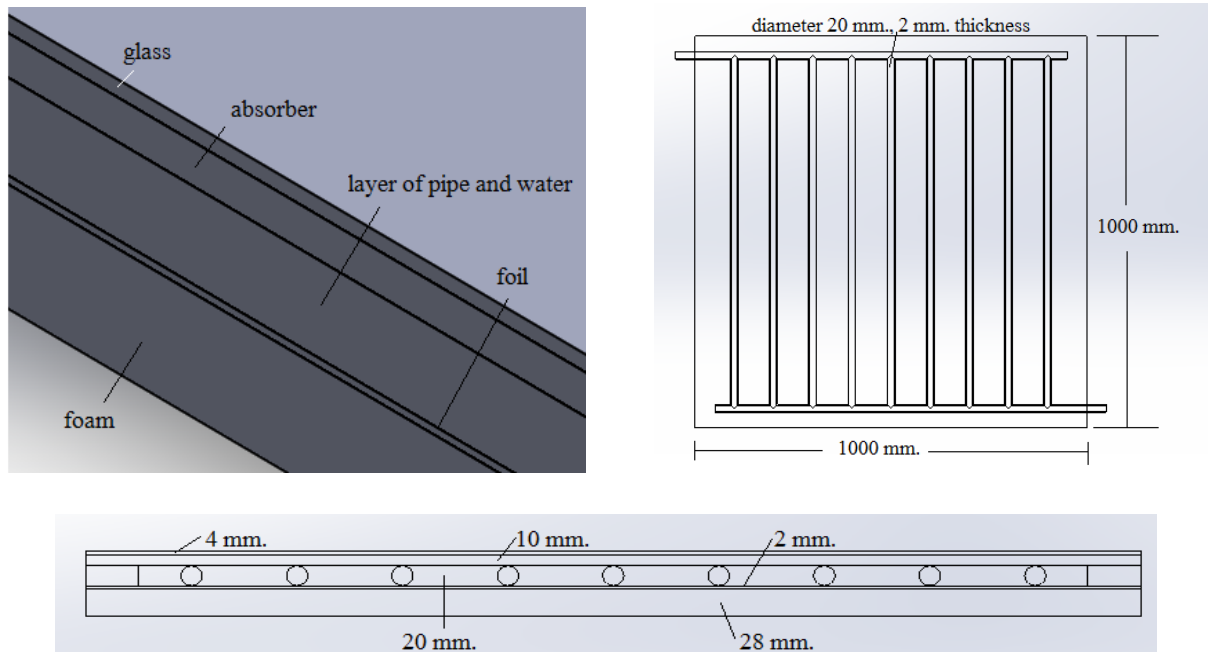

Fig. 3. Dimension of solar thermal

Table 1. Parameters of solar thermal simulation

\begin{tabular}{cccc}
\hline Material & $k\left(\mathrm{~W} / \mathrm{m} \cdot{ }^{\circ} \mathrm{C}\right)$ & $c\left(\mathrm{~J} / \mathrm{kg} \cdot{ }^{\circ} \mathrm{C}\right)$ & $\rho\left(\mathrm{kg} / \mathrm{m}^{3}\right)$ \\
\hline Glass & 1.05 & 840 & 2600 \\
Absorber (copper) & 400 & 385 & 8700 \\
Absorber (aluminum) & 205 & 896 & 2700 \\
Absorber (anodize aluminum) & 570 & 951 & 3200 \\
Air & 0.024 & 1005 & 1.2 \\
Foil & 0.0395 & 1200 & 2.6989 \\
Foam & 0.031 & 1500 & 30 \\
Pipe (copper) & 400 & 385 & 8700 \\
Water & 0.6 & 4187 & 100 \\
\hline
\end{tabular}


Table 2. Input details for thermal analysis in finite element

\begin{tabular}{cc}
\hline \multicolumn{2}{c}{ Input details for solar thermal } \\
\hline Initial temperature & $30{ }^{\circ} \mathrm{C}$ \\
Ambient temperature & $30{ }^{\circ} \mathrm{C}$ \\
Water inlet temperature & $30{ }^{\circ} \mathrm{C}$ \\
Top layer temperature (glass) & $40{ }^{\circ} \mathrm{C}$ \\
Inlet water velocity & $50 \mathrm{~mm} / \mathrm{sec}$ \\
Convective heat transfer of water & $20 \mathrm{~kJ} / \mathrm{kg}$ \\
$\Delta t$ & $1 \mathrm{sec}$ \\
Axis velocity of water flow & $-\mathrm{z}$ \\
\hline
\end{tabular}

\section{3-D FEM Simulation Result}

The FEM-based simulation conducted in the paper is coded with MATLAB programming for calculation of temperature distribution within solar thermal. To utilize a graphical feature of MATLAB, the graphical represent for temperature in Fig. 4., Fig. 6., and Fig. 8. show result when considered temperature distribution in solar thermal of copper absorber, aluminum absorber, and anodized aluminum absorber, respectively. Fig. 5., Fig. 7., and Fig. 9. show result of temperature distribution in water when considered copper absorber, aluminum absorber, and anodized aluminum absorber, respectively. Maximum and Minimum temperature in each layer of solar thermal when considered copper absorber, aluminum absorber, and anodized aluminum absorber are presented in Table 3., Table 4., and Table 5., respectively.

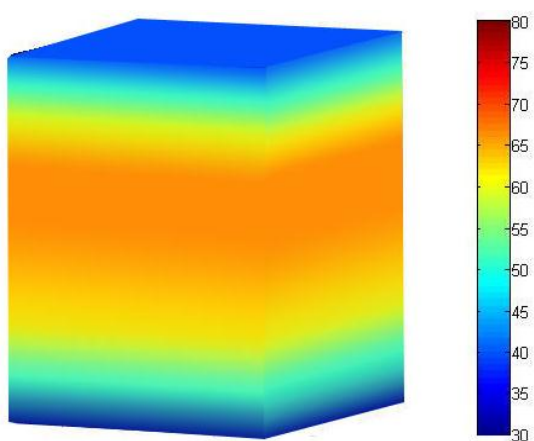

Fig. 4. Result of temperature distribution in solar thermal when considered copper absorber $\left({ }^{\circ} \mathrm{C}\right)$

a) $0 \mathrm{sec}$

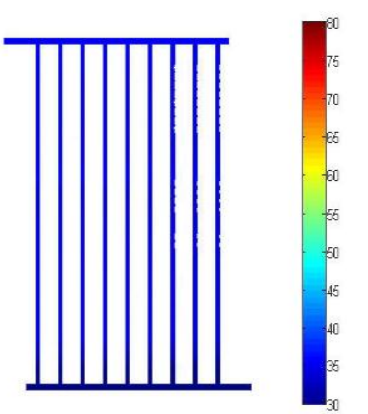

Fig. 5. Result of temperature distribution in water when considered copper absorber $\left({ }^{\circ} \mathrm{C}\right)$

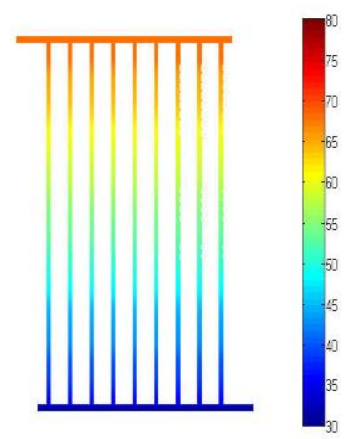

c) $20 \mathrm{sec}$

Table 3. Maximum and minimum temperature in solar thermal when considered copper absorber

\begin{tabular}{ccccccc}
\hline Results $\left({ }^{\circ} \mathrm{C}\right)$ & glass & absorber & pipe & water & foil & foam \\
\hline Max. temp. & 44.32 & 61.17 & 62.14 & $\frac{\mathbf{6 8 . 7 4}}{30}$ & 62.45 & 58.09 \\
Min. temp. & 40 & 44.32 & 61.98 & 58.09 & 30 \\
\hline
\end{tabular}




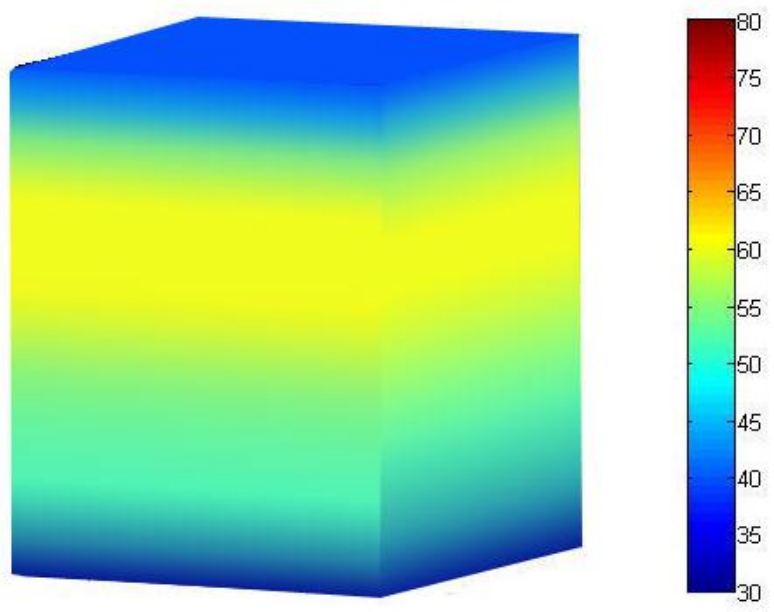

Fig. 6. Result of temperature distribution in solar thermal when considered aluminum absorber $\left({ }^{\circ} \mathrm{C}\right)$

a) $0 \mathrm{sec}$

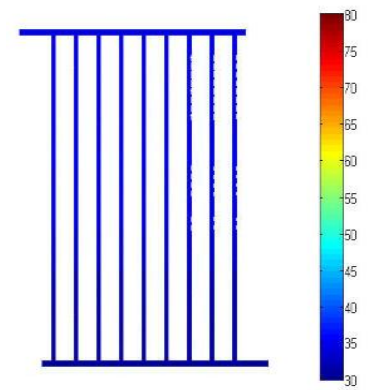

Fig. 7. Result of temperature distribution in water when considered aluminum absorber $\left({ }^{\circ} \mathrm{C}\right)$

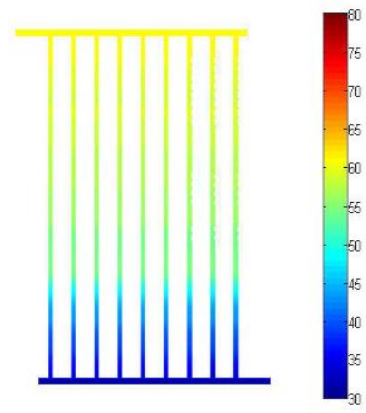

c) $20 \mathrm{sec}$

Table 4. Maximum and minimum temperature in solar thermal when considered aluminum absorber

\begin{tabular}{ccccccc}
\hline Results $\left({ }^{\circ} \mathrm{C}\right)$ & glass & absorber & pipe & water & foil & foam \\
\hline Max. temp. & 42.12 & 53.27 & 57.14 & $\underline{\mathbf{6 0 . 6 8}}$ & 56.48 & 55.12 \\
Min. temp. & 40 & 42.12 & 56.27 & 30 & 55.12 & 30 \\
\hline
\end{tabular}
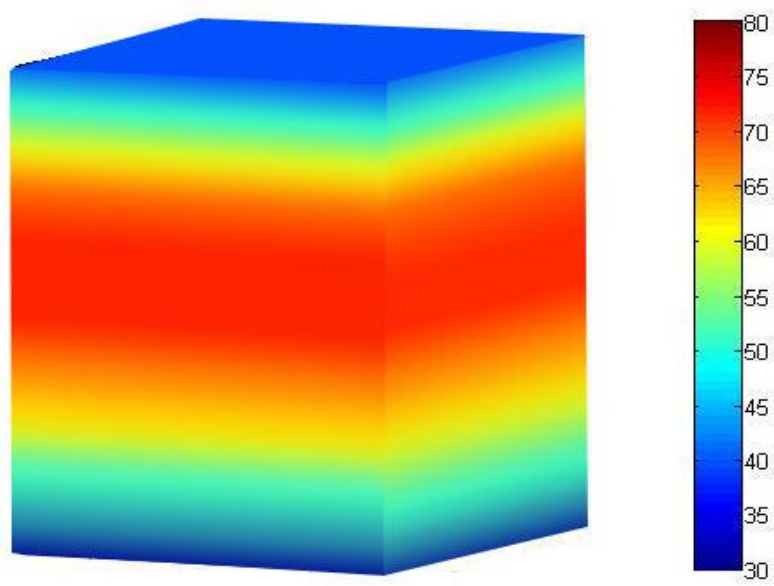

Fig. 8. Result of temperature distribution in solar thermal when considered anodize aluminum absorber $\left({ }^{\circ} \mathrm{C}\right)$ 


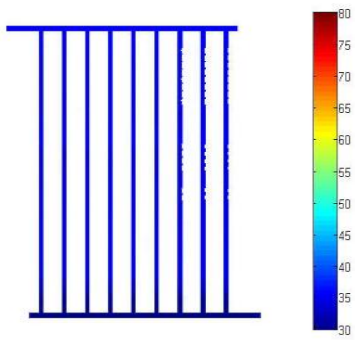

a) $0 \mathrm{sec}$

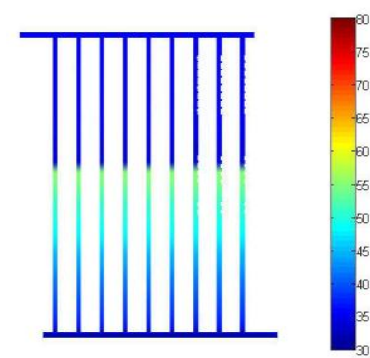

b) $10 \mathrm{sec}$

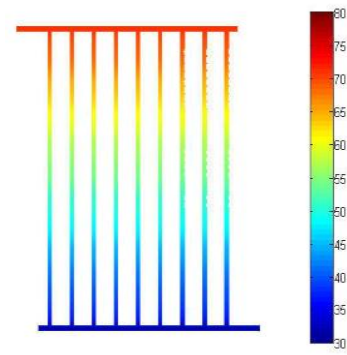

c) $20 \mathrm{sec}$

Fig. 9. Result of temperature distribution in water when considered anodize aluminum absorber $\left({ }^{\circ} \mathrm{C}\right)$

Table 5. Maximum and minimum temperature in solar thermal when considered anodize aluminum absorber

\begin{tabular}{ccccccc}
\hline Results $\left({ }^{\circ} \mathrm{C}\right)$ & glass & absorber & pipe & water & foil & foam \\
\hline Max. temp. & 52.36 & 65.72 & 62.39 & $\mathbf{7 2 . 3 6}$ & 66.41 & 60.87 \\
Min. temp. & 40 & 52.36 & 61.88 & 30 & 60.87 & 30 \\
\hline
\end{tabular}

From Fig. 4., Fig. 6., and Fig. 8. present result of temperature distribution in solar thermal when considered copper absorber, aluminum absorber, and anodized aluminum absorber, respectively which show that the temperature is higher up from glass layer $\left(40^{\circ} \mathrm{C}\right)$ to absorber then go to layer of water respectively due to heat accumulation when sunlight touch solar thermal and heat transfusion from absorber to pipe which pipe will transfer the heat to water. So the water gets maximum temperature. After that, foil and foam will be an insulator by not let the heat out then temperature will be lower from water pipe to foil and foam till the temperature rate is ambient temperature $\left(30^{\circ} \mathrm{C}\right)$ of solar thermal.

From Fig .5, Fig. 7, and Fig. 9 present result of temperature distribution in water when considered copper absorber, aluminum absorber, and anodized aluminum absorber, respectively, which show that when the water is released, the temperature is not changed much since the heat accumulation is not enough to transfer heat to absorber. But when heat accumulation can transfer heat to absorber, the water will be changed very fast. Water is steady state because water flow out continuously and new water will replace the old part. The temperature will be higher from the bottom zone that water inlet into above zone that water flow outlet because of heat accumulation in every time that water is flowing. From a) $0 \mathrm{sec}$, Fig .5., Fig. 7., and Fig. 9., it is the first picture show when sunlight transfer the heat to water. Water outlet at steady state has maximum temperature is $68.74{ }^{\circ} \mathrm{C}, 60.68{ }^{\circ} \mathrm{C}, 72.36{ }^{\circ} \mathrm{C}$ when considered copper absorber, aluminum absorber, and anodized aluminum absorber, respectively. Which water outlet anodized aluminum absorber is the maximum temperature.

Form Table 3, Table 4, and Table 5 show maximum temperature and minimum temperature in each layer of solar thermal when considered copper absorber, aluminum absorber, and anodized aluminum absorber, respectively. The anodized aluminum absorber has the maximum water temperature. Next, the water temperature of copper absorber and the least is water temperature of aluminum absorber. Due to anodized aluminum has conductivity is the maximum rate then the copper and the least is aluminum.

\section{Conclusion}

This article investigated the temperature that took place in solar thermal. The sample model from computer applied the 3-D FEM which developed by MATLAB. This paper is time-dependent field which is improved by discretizing time. It can be observed that the temperature of the anodized aluminum absorber has the maximum water temperature. Next, the water temperature of copper absorber and the least is water temperature of aluminum absorber.

\section{Acknowledgements}

This work was supported by School of Electrical Engineering, Institute of Engineering, Suranaree University of Technology. 


\section{References}

[1] Pao-la-or P, Peaiyoung S, Kulworawanichpong T, Sujitjorn S. Magnetic field simulation of an induction motor using nonlinear time-stepping finite element method, In: Proc. of $2^{\text {th }}$ International Conference on Electrical Engineering/Electronics, Computer, Telecommunications and Information Technology (ECTI-CON 2005), $2005 ; 734$ - 737.

[2] Pao-la-or P, Isaramongkolrak A, Kulworawanichpong T. Finite element analysis of magnetic field distribution for 500-kV power transmission systems. Engineering Letters, 2010; 1(1):1-9.

[3] Pao-la-or P. Study of magnetic field shielding roof of cabin electricity authority resulting in operators working WSEAS Transaction on Power System, 2011; 6(10):163-172.

[4] Bunmat A, Pao-la-or P. Analysis of magnetic field effects operators working a power transmission line using 3-D finite element method. In: Proc. of 18 th International Conference on Electrical Machine and System (ICEMS), Oct. 25-28, Pattaya City, Thailand.:1187-1191.

[5] Vacharakup S, Peerasaksophol M, Kulworawanichpong T, Pao-la-or P. Study of natural frequencies and characteristics of piezoelectric transformers by using 3-D finite element method. Applied Mechanics and Materials, 2012; 110-116:61-66.

[6] Sheeba JB, Rohini AK, Structural and thermal analysis of asphalt solar collector using finite element method. Journal of Energy, 2014; 9.

[7] Roos A, Georgson M. Tin-oxide-coated anodized aluminium selective absorber surfaces II. Aging and durability. Journal of Energy, March 1991; 22(1): 29-41.

[8] Lewis RW, Nithiarasu P, Seetharamu KN, Fundamentals of the Finite Element Method for Heat and Fluid Flow, John Wiley \& Sons, US, 2004.

[9] Bhatti MA, Advanced Topics in Finite Element Analysis of Structures, John Wiley \& Sons, USA, 2006.

[10] Kattan PI, MATLAB Guide to Finite Elements (2nd edition), Springer Berlin Heidelberg, USA, 2007.

[11] Jabbar MA, Phyu HN, Liu ZJ, Bi C. Modeling and numerical simulation of a brushless permanent-magnet dc motor in dynamic conditions by time-stepping technique. IEEE Transactions on Industrial Applications, 2004; 40(3): 763-769.

[12] Amornsawatwattana I, Pao-la-or P, Analysis of temperature in solar thermal by 3-D finite element method, $5^{\text {th }}$ International Electrical Engineering Congress, Pattaya, Thailand, March 2017; 2:208-211. 